\title{
Extended levobunolol release from Eudragit nanoparticle-laden contact lenses for glaucoma therapy
}

\author{
Navneet Kumar ${ }^{*}$ D, Rohan Aggarwal and Meenakshi K. Chauhan
}

\begin{abstract}
Background: Majorly, the reason for the permanent loss of vision is glaucoma. But the currently available common treatment methodologies such as eye drops have various disadvantages like patient incompliance due to repeated administration and poor (1-5\%) bioavailability leading to poor efficiency. The objective of this research was to formulate Eudragit-based nanoparticles of levobunolol incorporated into a contact lens to obtain sustained ocular delivery of levobunolol at the therapeutics level. Eudragit nanoparticles of levobunolol were formulated by nanoprecipitation methodology utilizing different ratios of Eudragit S100 and polyvinyl alcohol. The prepared nanoparticles were evaluated and optimized by efficiency of entrapment, particle size, morphology of surface and zeta potential. The optimized nanoparticles were then entrapped into the matrix of the contact lens by the soaking method which were then characterized and compared for optical clarity study, equilibrium swelling study, shelf life and in vitro drug release in simulated tear fluid followed by ex vivo transcorneal permeation study.

Results: Formulation F3 was obtained as optimized nanoparticle formulation with $102.61 \mathrm{~nm} \pm 3.92$ of particle size, $-22.2 \mathrm{mV} \pm 2.76$ of zeta potential and $86.995 \% \pm 1.902$ of efficiency of entrapment. The equilibrium swelling index and transmittance of nanoparticle incorporated into contact lenses showed better results when compared to drug solution-loaded lenses. In vitro release indicated more sustained drug profiles $(84.33 \% \pm 0.34$ of drug release over a period of 12 days) as compared to drug solution-loaded lenses $(89.282 \% \pm 0.900$ of drug release over a period of 3 days). Ex vivo transcorneal permeation studies showed more permeation $(6.75 \% \pm 0.170)$ through contact lenses as compared to marketed eye drops $(3.03 \% \pm 0.088)$.

Conclusion: This research demonstrates the remarkable results of drug-laden contact lenses to serve as a great medium for the continued delivery of ocular drugs without affecting the physical and optical characteristics of the lens content.
\end{abstract}

Keywords: Levobunolol, Eudragit S100, Polyvinyl alcohol, Nanoparticle, Contact lens, Sustained delivery

\section{Background}

Glaucoma is the world's number one cause of permanent loss of vision. Glaucoma impacts over 70 million people globally, with around $10 \%$ becoming bilaterally blind, leading to permanent visual impairment. Glaucoma is associated with asymptomatic symptoms until it

\footnotetext{
* Correspondence: nkshrivastav97@gmail.com

Department of Pharmaceutics, Delhi Institute of Pharmaceutical Sciences and Research, Mehrauli - Badarpur Rd, Sector 3, Pushp Vihar, New Delhi 110017,
} India

becomes severe, creating a high probability that the people most affected will be much larger than the number reported to possess it. Glaucoma is a very serious Glaucoma management has no permanent cure, so its treatment regimen is very long and it is also very difficult for the patient to remember to instil eye drops every day. Conventional eye drops are the most common eye disease management approaches, but they are highly 
ineffective due to a poor bioavailability of less than 1$5 \%$. As the drug is maintained in the eye for a relatively short duration, eye drops are instilled 3 to 4 times every day, often in large doses. Frequent eye drop administration leads to incompliance in patients and causes sensitivity reactions, pigmentation of the cornea and mechanical injury of the conjunctiva and eyelid. The currently available anti-glaucoma drug formulations are not very effective as the concentration of the drug increases initially but it drops below the effective concentration very soon. As a result, the intraocular pressure rises and declines. Therefore, ocular therapies with such classes of drug can be significantly improved by interventions with the ophthalmic drug delivery system $[4,5]$.

Contact lenses are being used for medication delivery into the eyes from the past few years. Such lenses are primarily used for the correction of eye refractive errors. Simultaneous correction of the refractive error would provide a prominent complement to the use of contact lenses and thus receive drug treatment simultaneously. Several studies have suggested lenses for controlled delivery of drugs as a medical aid. Since it shows bioavailability of far more than 50\% relative to the eye drop treatment, the utilization of contact lenses as a system for delivery of medications has a growing interest in enhancing the effectiveness of eye care. Contact lenses lead to dose reduction, increased bioavailability, increased residence time and reduced side effects [6, 7].

The major drawback of contact lens soaked with a drug is shorter drug diffusion which is unable to obtain sustained delivery of the drug. Thus, to overcome this, it has been suggested that formulations based on vesicular carriers can maintain the medication in cold storage during storage as well as provide prolonged release after incorporation into the eyes as recorded in different studies. Sustained and controlled release of the drug was obtained from microemulsion-, microparticle-, and nanoparticlebased formulations $[8,9]$. Also, medication-loaded microparticles and nanoparticles into the matrix contact lens can retain its optical and physical characteristics $[10,11]$.

Levobunolol (LB) is an effective non-selective betaadrenergic blocker utilized for the treatment of glaucoma effectively. Levobunolol $\mathrm{HCl}$ (hydrochloric acid) is more than 60 times more potent in its beta-blocking activity than its dextro-isomer (bunolol). Many studies have shown that the levobunolol shows the same efficiency as of timolol in beta-blocking activity with better absorption of the ocular and 10 times greater elimination. Levobunolol lowers mean intraocular pressure (IOP) from baseline by around 30 to $40 \%$ in glaucoma patients with elevated IOP [12-14]. For the diagnosis of open-angle glaucoma as a first-line medication, Betagan ${ }^{\odot}$ eye drop (containing $0.5-1 \%$ of levobunolol) is recommended [15].
The purpose of this research was to formulate therapeutic contact lenses loaded with levobunolol nanoparticles for the effective treatment of glaucoma. Eudragit S100 (ES 100) was utilized for the development of Eudragit-based nanoparticles incorporating levobunolol. The Eudragit S100 has dissolution behaviour that shows characteristic release above $\mathrm{pH}$ 7.0. Hence, it was utilized to provide $\mathrm{pH}$-dependent sustained drug release from the matrix of nanoparticles at the $\mathrm{pH}$ of tear fluid, i.e. $7.4[16,17]$. Due to the positioning of lenses upon the cornea segregated by a thin fluid layer called post-lens tear film (POLTF), ophthalmic drugs can be administered very easily through the contact lens, as shown in Fig. 1. The time of residence of the drug in the POLTF is around $30 \mathrm{~min}$, that is, substantially greater than those of eye drop drugs $(5 \mathrm{~min})$. Once these therapeutic contact lenses are positioned on the surface of the eye, the medication gradually diffuses from the matrix of the nanoparticle, passes via the lens structure and reaches the post-lens and pre-lens tear film, with far more long retention time compared to eye drops [18-20].

The prepared nanoparticle formulation was evaluated and optimized utilizing parameters such as entrapment efficiency, zeta potential and particle size. Furthermore, levobunolol nanoparticle (LB-NP)-loaded contact lens was evaluated for physical appearance, surface $\mathrm{pH}$, transmittance, equilibrium swelling study, etc. In vitro studies with LB-ES 100 nanoparticleloaded contact lenses were conducted and matched with the drug permeated through marketed eye drop formulation of the same drug (i.e. Betagan ${ }^{\circledR}$ ). Similarly, ex vivo transcorneal permeation studies were also conducted using goat cornea as a membrane. Hence, the proposed research work was concerned to establish the potential advantage of sustained action of LBNP-laden contact lenses for the delivery of drugs into the ocular system for the effective treatment of glaucoma.

\section{Methods \\ Materials}

Levobunolol and Eudragit S100 were procured as a gift sample from the Piramal Healthcare Pvt. Ltd., Mumbai, India, and Evonik India Pvt. Ltd., Mumbai, India, respectively. Polyvinyl alcohol was purchased from Central Drug House, Lab Reagents, Delhi, India. Aqualens Slipon $^{\oplus}$ (Omafilcon A) contact lenses manufactured by Aqua Lens Pvt. Ltd., Haryana, India, were used in this study. Fresh goat eyes were purchased from a local butcher's shop. $0.5 \%$ eye drop of levobunolol was purchased from a local pharmacy. All other solvents and chemicals were of analytical grade. 


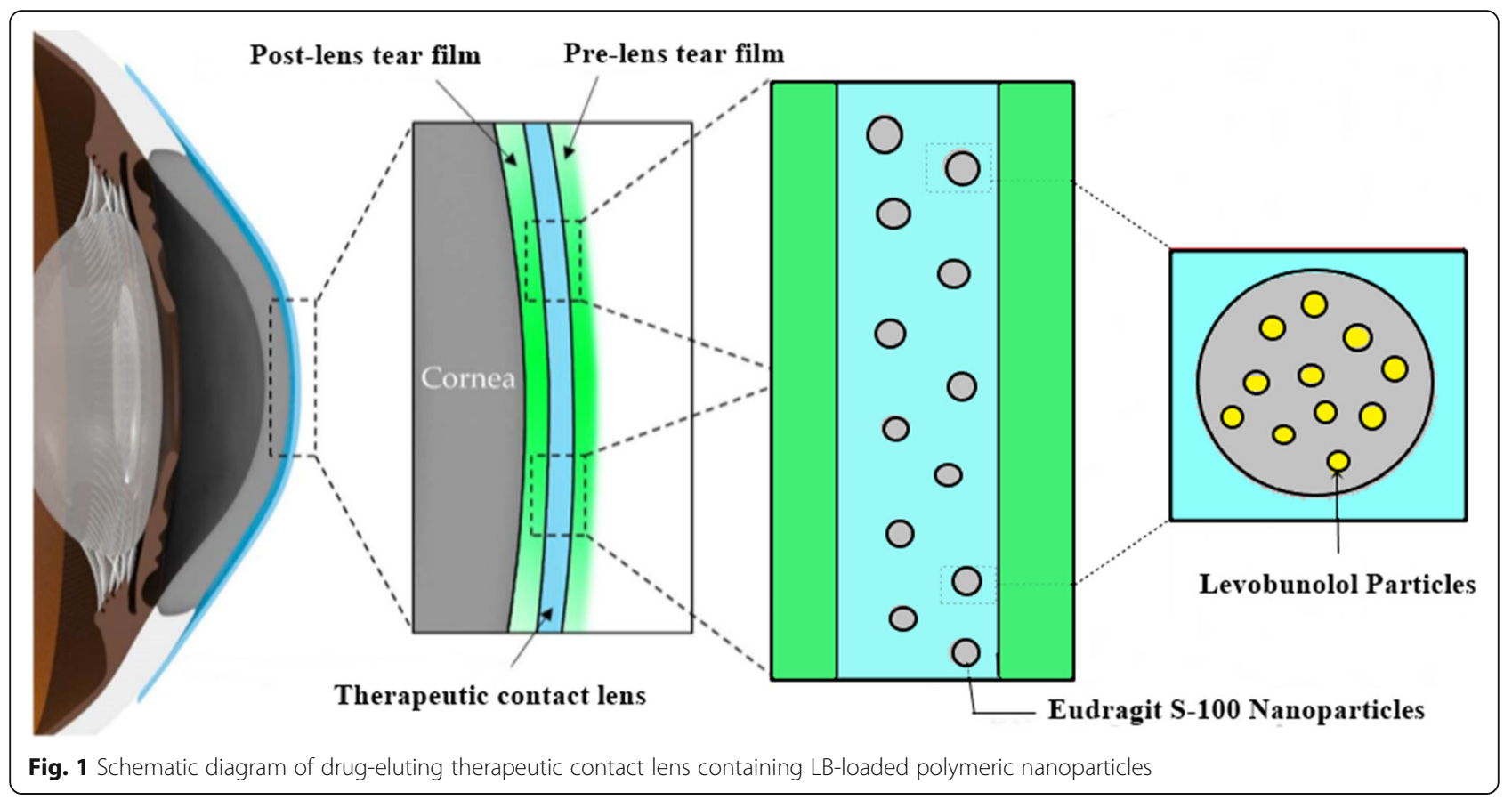

\section{Drug excipient interaction study}

Fourier transform infrared analysis (FTIR) spectra were obtained on a PerkinElmer FTIR spectrometer, USA. Powdered sample spectra were obtained using the method of potassium bromide discs. In each case, the spectra were collected in the area $400-4000 \mathrm{~cm}^{-1}$ to study the interaction between the drug's and polymer's physical mixture.

\section{Formulation of LB-loaded Eudragit S100 nanoparticles}

The encapsulated LB nanoparticles were formulated by using the nanoprecipitation methodology as shown in Fig. 2. Different concentration ratios (1:1, 2:1, 1:3 and 3: 2) of Eudragit S100 and polyvinyl alcohol (PVA) were taken for nanoparticle formulation. An aqueous solution of PVA and LB $(5 \mathrm{mg} / \mathrm{mL})$ was prepared, and then Tween 80 (1\%) was added into it. Separately, an organic

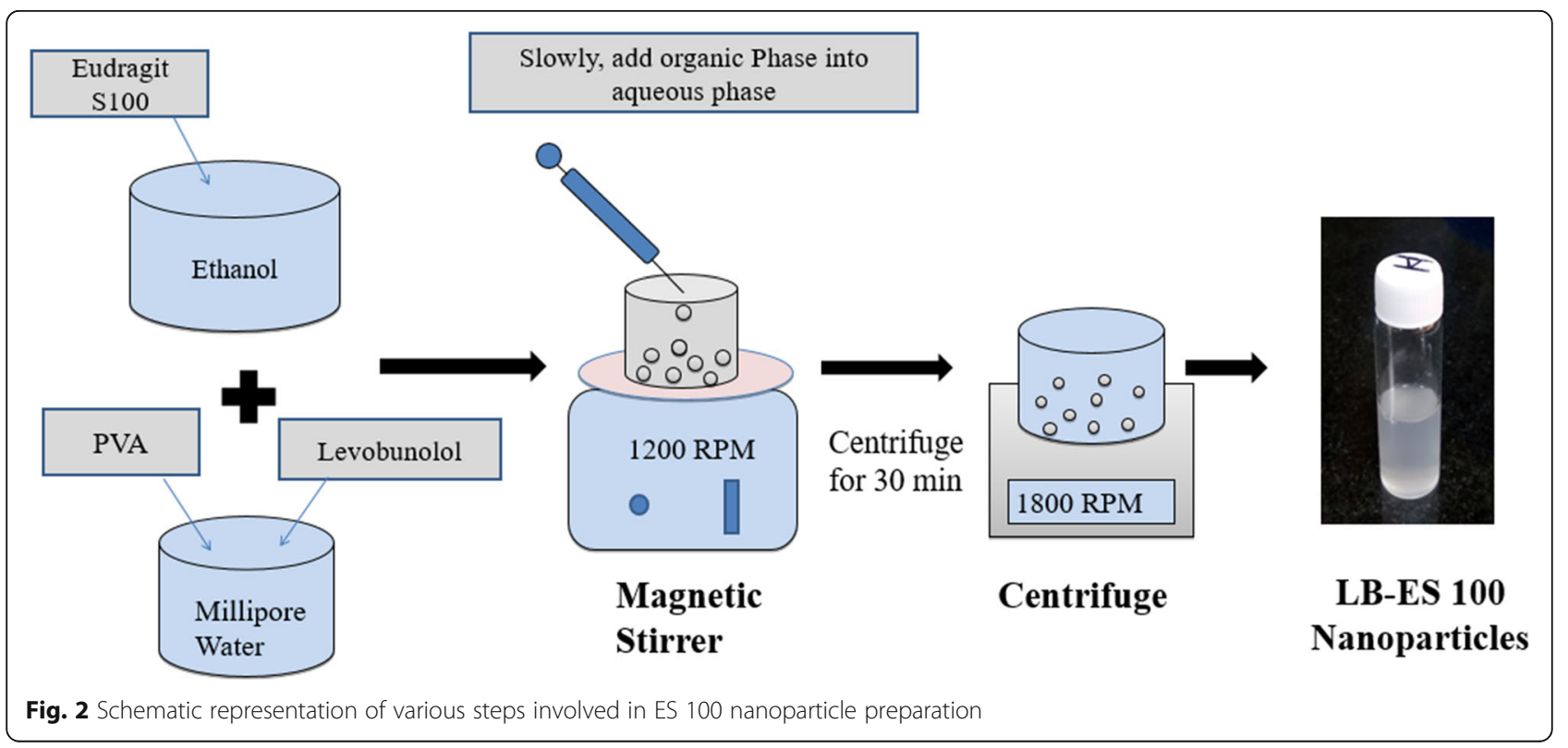


solution of Eudragit S100 in ethanol was prepared and then added to the aqueous solution dropwise under continuous magnetic stirring at $800 \mathrm{rpm}$ at $25^{\circ} \mathrm{C}$. Tween 80 was added in the aqueous phase in order to avoid polymer aggregation. Through evaporation, the organic phase is completely removed, leaving the nanoparticles suspended in the aqueous phase. After the organic solvent evaporates, the prepared nanoparticles were centrifuged at $18,000 \mathrm{rpm}, 4{ }^{\circ} \mathrm{C}$ for $30 \mathrm{~min}$, and nanoparticles obtained after centrifugation were washed with distilled water several times and kept at $4{ }^{\circ} \mathrm{C}$ [21-23].

The following mentioned ratios of ES100 and PVA as shown in Table 1 are used for the LB-NP preparation. The final selection of optimized particles for loading in contact lenses was determined on the basis of the results of particle size distribution, zeta potential and efficiency of entrapment of all the formulations.

\section{Characterization and optimization of Eudragit S100 nanoparticles}

The formulated nanoparticles were characterized and optimized on the basis of the parameters listed below.

\section{Physiochemical evaluation}

Particle size, zeta potential and polydispersity index of ES 100 nanoparticles were obtained by utilizing Nicomp ${ }^{\circ}$ N3000 PSS sizing system (USA) which uses the principle of dynamic light scattering (DLS). The prepared nanoparticles were diluted 5 times with distilled water and sonicated for $10 \mathrm{~min}$. Triplicate readings were determined $[24,25]$.

\section{Drug entrapment study}

The entrapped LB in ES 100 nanoparticles was obtained by the centrifugation method, which involves separation of the entrapped drug from nanoparticles. For this, $1 \mathrm{~mL}$ of each formulation was taken which was centrifuged at $15,000 \mathrm{rpm}$ for $30 \mathrm{~min}$ at $4{ }^{\circ} \mathrm{C}$ by cooling centrifuge (R$8 \mathrm{C}$, Remi instruments, Mumbai, India). The supernatant was obtained and evaluated at $257 \mathrm{~nm}$ by an ultraviolet- visible spectrophotometer (UV 1800, Shimadzu, USA) for LB concentration. The same procedure was repeated with all ratios of formulation prepared taking $n=3[26$, 27]. The percentage entrapment efficiency of LB was calculated using the equation given below:

$$
\begin{aligned}
\text { Entrapment efficiency }= & \frac{\text { Calculated drug content }}{\text { Theoretical drug content }} \\
& \times 100
\end{aligned}
$$

\section{Transmission electron microscopy (TEM)}

The prepared Eudragit nanoparticles were characterized by TEM at $300 \mathrm{kV}$ (JEOL 2100F, USA) to determine size and surface morphology. A drop of prepared dispersion was stratified over a carbon film-covered copper grid for approximately $15 \mathrm{~min}$ and then negatively stained with $0.1 \%$ phosphotungstic acid. The sample was allowed to air dry and examined with a Hitachi H-7500 transmission electron microscope (Hitachi Ltd., Tokyo, Japan) at an accelerating voltage of $80 \mathrm{kV}$.

\section{Development of levobunolol nanoparticle-loaded contact lens \\ Selection of contact lenses}

As the present study involves continuous lens wear for few days, it is very important that the contact lenses selected for the study should not interfere with the normal vision of the patient, should be comfortable to wear and provide sufficient water content and oxygen permeability to prevent hypoxia and should have minimal chances of causing any eye infections [28]. Five types of contact lenses were purchased from various manufacturers in India for the study and were checked for their water content and oxygen permeability.

\section{Loading of LB-NPs into the matrix of contact lenses}

The soaking method was employed for the loading of LB-NPs into the matrix of contact lenses. Primarily, the contact lenses were soaked for $10 \mathrm{~min}$ in $30 \mathrm{~mL}$ of

Table 1 Formulation composition of ES 100 nanoparticles

\begin{tabular}{|c|c|c|c|c|c|}
\hline Formulation code & Ratio ES 100:PVA & ES 100 (\%) & PVA (\%) & Tween 80 (\%) & Drug (mg) \\
\hline F1 & $1: 1$ & 0.5 & 0.5 & 1 & 50 \\
\hline F2 & $2: 1$ & 1 & 0.5 & 1 & 50 \\
\hline F3 & $3: 2$ & 1.5 & 1 & 1 & 50 \\
\hline F4 & $1: 2$ & 0.5 & 1 & 1 & 50 \\
\hline F5 & $1: 3$ & 0.5 & 1.5 & 1 & 50 \\
\hline F6 & $2: 3$ & 1 & 1.5 & 1 & 50 \\
\hline F7 & $3: 1$ & 1.5 & 0.5 & 1 & 50 \\
\hline
\end{tabular}


Millipore water. They were then submerged in $10 \mathrm{~mL}$ of ethanol for $10 \mathrm{~min}$, resulting in swelling and an increase in the contact lens thickness, which would further improve the drug uptake by the lenses. Then, each lens was then soaked in $5 \mathrm{~mL}$ of LB-NPs $(5 \mathrm{mg} / \mathrm{mL})$ solution for $24 \mathrm{~h}$. After loading, the lenses were blotted to remove any residual surface drug solution by using clean filter paper (without lint) and then used for further studies [29].

\section{Therapeutic dose estimation}

The prescribed dose of Betagan ${ }^{\circ}$ eye drop $(0.5 \%$ w/v solution of LB solution) is 1 drop 2 times daily for glaucoma therapy with $50 \mu \mathrm{L}$ of volume remained in the eye. Thus, a drop administered twice a day would yield $500 \mu \mathrm{g}$ of levobunolol per day but levobunolol bioavailability obtained by eye drops is just about $5 \%$. Levobunolol's clinical requirement from the contact lens is about $25 \mu \mathrm{g}$ per day as its bioavailability is $50 \%[15,30,31]$.

\section{Characterization of prepared LB-NP-loaded contact lenses Physical appearance}

The physical appearance of NP-loaded contact lenses was judged visually for transparency and change in colour.

\section{Optical clarity studies}

LB-NP contact lenses' optical properties should not alter after nanoparticle loading. Thus, the percentage transmittance through contact lenses was determined. For clear vision, more than $90 \%$ of transmittance should be achieved. The control contact lens was hydrated for $24 \mathrm{~h}$ by soaking in simulated tear fluid, and placed in a quartz cuvette and scanned in a UV spectrophotometer (UV 1800, Shimadzu, Japan) at wavelengths ranging from 200 to $1000 \mathrm{~nm}$. Similarly, transmittance of LB-NP contact lenses has been noted and results have been compared with the standard to obtain any significant changes in optical clarity that may affect normal vision compared to the marketed contact lens [24]. The values of absorbance of the subsequent lens were determined and the values of transmission (\%) were obtained using the formula:

$$
A=2-\log _{10} \% \mathrm{~T}
$$

where $A=$ absorbance and $\% \mathrm{~T}=$ percentage transmittance

\section{Equilibrium swelling study}

Equilibrium swelling percentage was determined using the mass balance method. This study was carried out by placing contact lenses in LB nanoparticles until the equilibrium was achieved. After $24 \mathrm{~h}$ of swelling, the tissue was utilized to dry the lenses and weighed ( $\left.W_{\text {wet }}\right)$ in air utilizing sensitive balance weighing (Sartorius). After this step, the lenses were allowed to dry and the initial dry weight $\left(W_{\text {dry }}\right)$ was determined. The ratio of swelling at equilibrium was determined by the equation:

$$
\begin{aligned}
& \text { Equilibrium swelling index } \\
& =\frac{W \text { wet }-W \text { dry }}{W \text { wet }} \times 100
\end{aligned}
$$

The swelling index of LB-NP-loaded contact lenses was then matched to that of the contact lenses marketed in order to understand any major variables in the study due to loading $[26,31]$.

\section{In vitro drug release in simulated tear fluid}

The LB-NP-loaded contact lenses were positioned in 3 $\mathrm{mL}$ of simulated tear fluid (STF $\mathrm{pH} 7.4$ ) at the room temperature in $5-\mathrm{mL}$ glass tubes and kept in a shaking incubator at $100 \mathrm{rpm}$ for the release study. The release medium volume was selected to be $3 \mathrm{~mL}$ roughly equivalent to the in vivo conditions of normal tear turnover of the human eye. The simulated tear fluid was substituted with the equal volume $(1 \mathrm{~mL})$ of fresh simulated tear fluid at each interval (every $24 \mathrm{~h}$ ), in order to obtain perfect sink conditions. The dynamic concentration of the drug in tear fluid was estimated using a UV-visible spectrophotometer (UV 1800, Shimadzu, Japan) to measure the absorbance at $257 \mathrm{~nm}$. Levobunolol release profile was assessed by plotting graphs of cumulative drug release $(\mu \mathrm{g})$ versus time. The experiments were conducted in triplicates [32, 33].

\section{Determination of drug release kinetics}

To determine the kinetics of release of medication from LB-NP-laden contact lenses, the in vitro release data was fitted in Higuchi models, Peppas, first order and zero order [34].

\section{Ex vivo transcorneal permeation study}

The ex vivo transcorneal permeation studies demonstrate the effect of the prepared LB-loaded contact lenses on the corneal permeation. Goat cornea excised freshly, free of adhering sclera was first fixed between donor and acceptor compartments of modified Franz diffusion cell in such a way that the epithelial surface faced the donor compartment and the endothelial surface faced the receptor section. The region available for diffusion on the cornea was $0.50 \mathrm{~cm}^{2}$. Simulated tear fluid $(\mathrm{pH} 7.4)$ of volume $10 \mathrm{~mL}$ was added to the receptor compartment. The contact lenses loaded with the LB-NPs were then placed on the top of the cornea surface. A Teflon-coated magnetic stirred bead was used to keep the receptor fluid at $37^{\circ} \mathrm{C}$. One milliliter of the sample was removed from the receiver compartment and replaced by the 

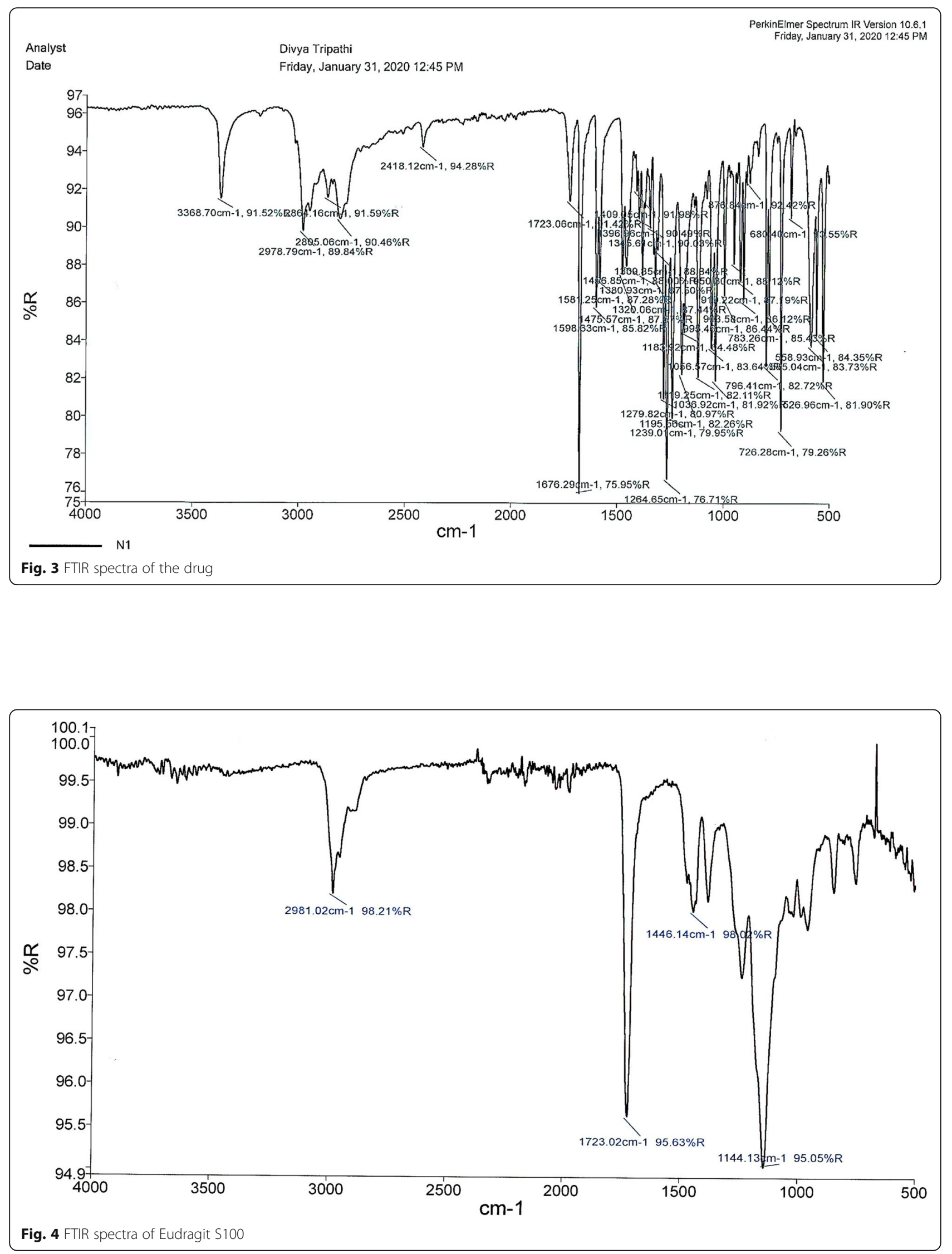

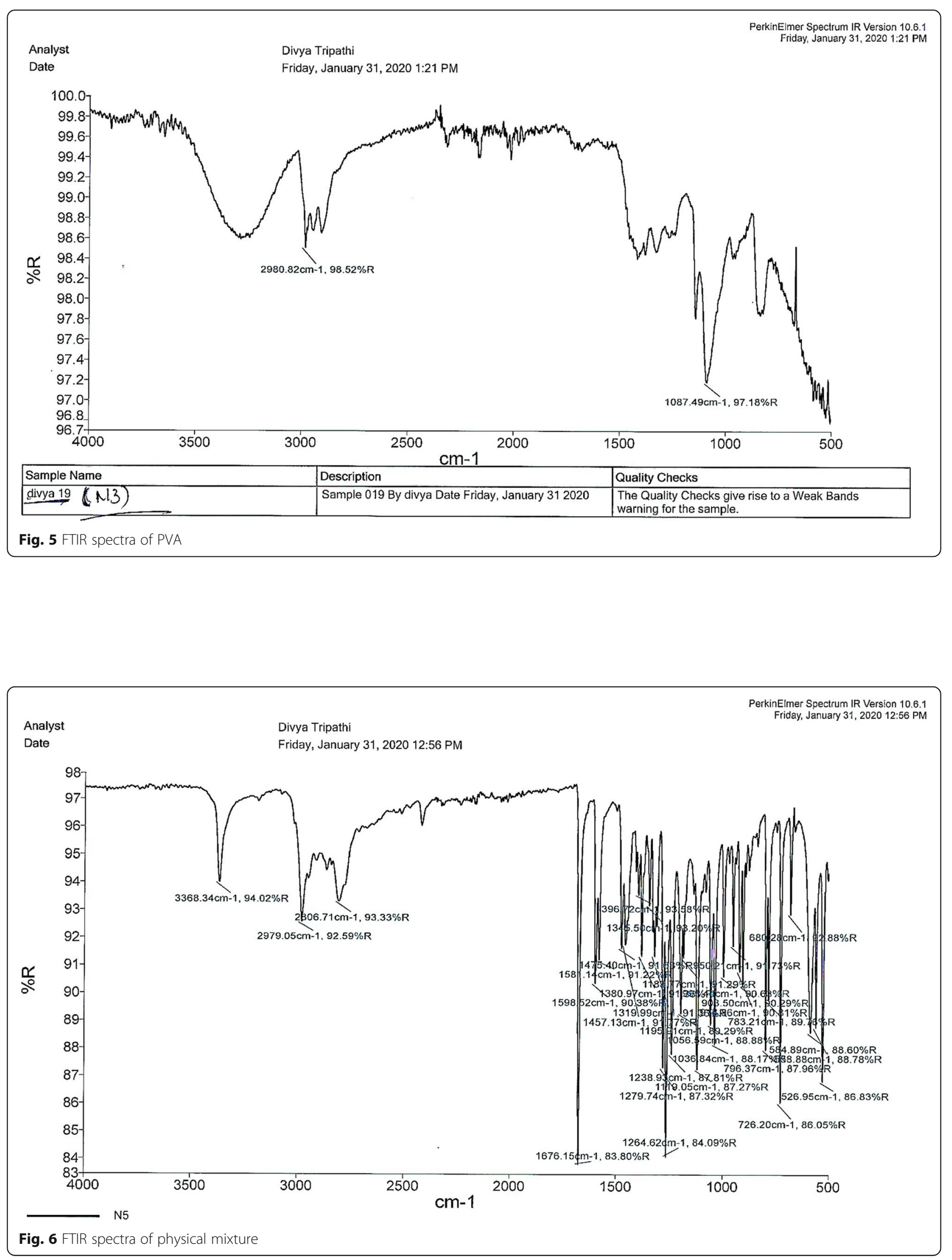
Table 2 Data showing particle size distribution, zeta potential and entrapment efficiency in different nanoparticle formulation

\begin{tabular}{lllll}
\hline Formulation code & Particle size $(\mathbf{n m}) \pm$ SD & Zeta potential $(\mathbf{m V}) \pm$ SD & PDI \pm SD & Entrapment efficiency $(\%) \pm$ SD \\
\hline F1 & $235.87 \pm 6.87$ & $-29.9 \pm 2.13$ & $0.341 \pm 0.039$ & $67.701 \pm 1.902$ \\
F2 & $135.04 \pm 6.93$ & $-22.3 \pm 4.72$ & $0.485 \pm 0.074$ & $80.564 \pm 2.938$ \\
F3 & $102.61 \pm 3.92$ & $-22.2 \pm 2.76$ & $0.415 \pm 0.027$ & $86.995 \pm 1.902$ \\
F4 & $304.62 \pm 15.56$ & $-18.3 \pm 5.95$ & $0.372 \pm 0.055$ & $63.152 \pm 1.245$ \\
F5 & $233.55 \pm 5.920$ & $-23.8 \pm 5.39$ & $0.338 \pm 0.060$ & $70.524 \pm 2.414$ \\
F6 & $150.04 \pm 7.74$ & $-29.7 \pm 2.02$ & $0.368 \pm 0.030$ & $77.113 \pm 2.591$ \\
F7 & $168.61 \pm 13.56$ & $-26.18 \pm 3.55$ & $0.387 \pm 0.032$ & $68.172 \pm 2.121$ \\
\hline
\end{tabular}

same volume of simulated tear fluid for maintaining sink conditions. All samples were analysed in a UV-visible spectrophotometer (UV 1800, Shimadzu, Japan) for LB content by determining absorbance at $257 \mathrm{~nm}$. Likewise, LB solution-loaded contact lenses were also used to study transcorneal permeation through goat cornea to achieve comparative results. The permeation was studied for $6 \mathrm{~h}$, and all the experiments were undertaken in triplicate [35, 36]. Percentage transcorneal permeation has been measured as:

Permeation $(\%)=$

$$
x=\frac{\text { Amount of drug permeated in receptor }}{\text { Drug uptake by contact lens }} \times 100
$$
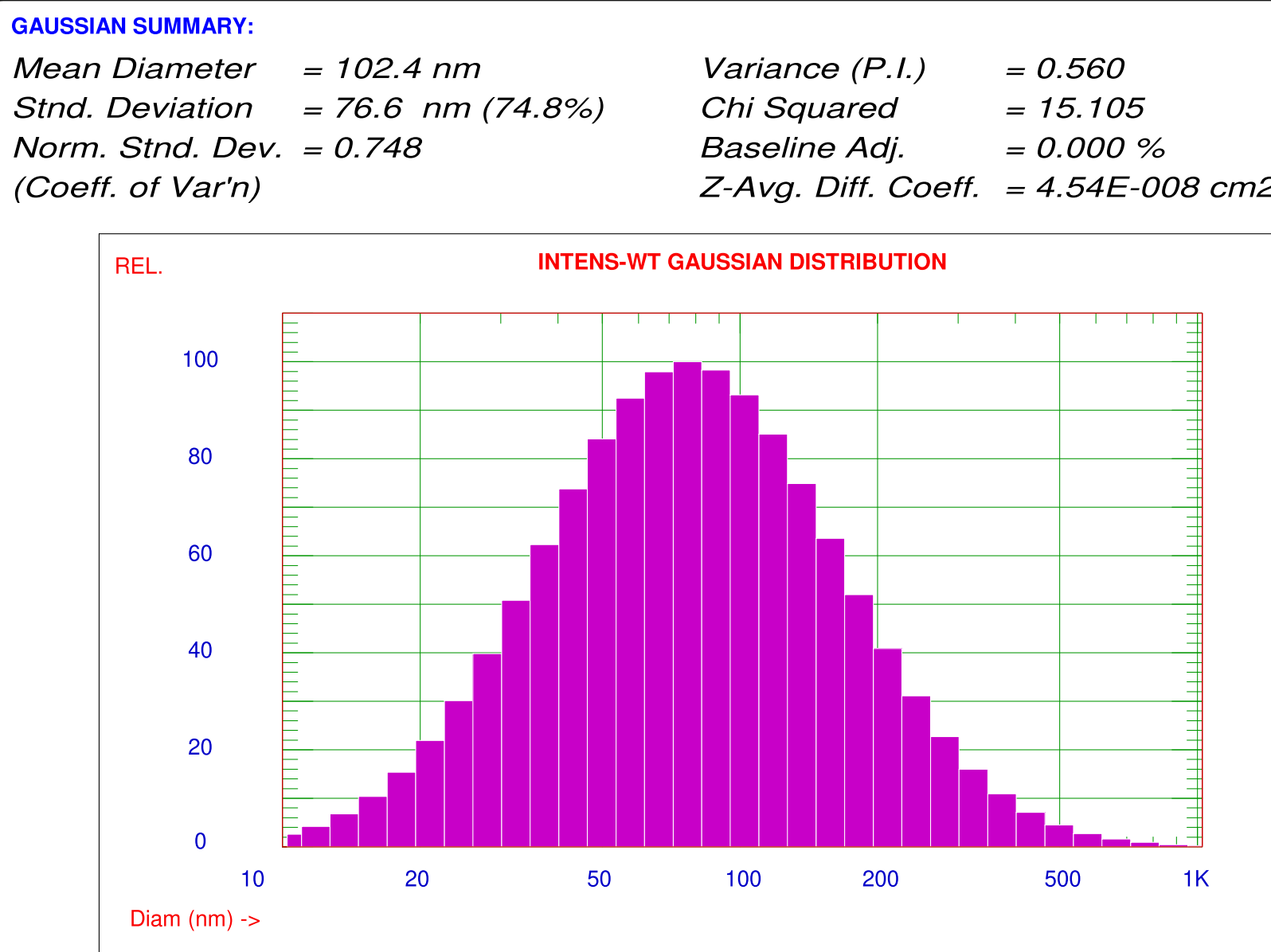

Fig. 7 DLS report for the particle size of the optimized nanoparticle formulation 


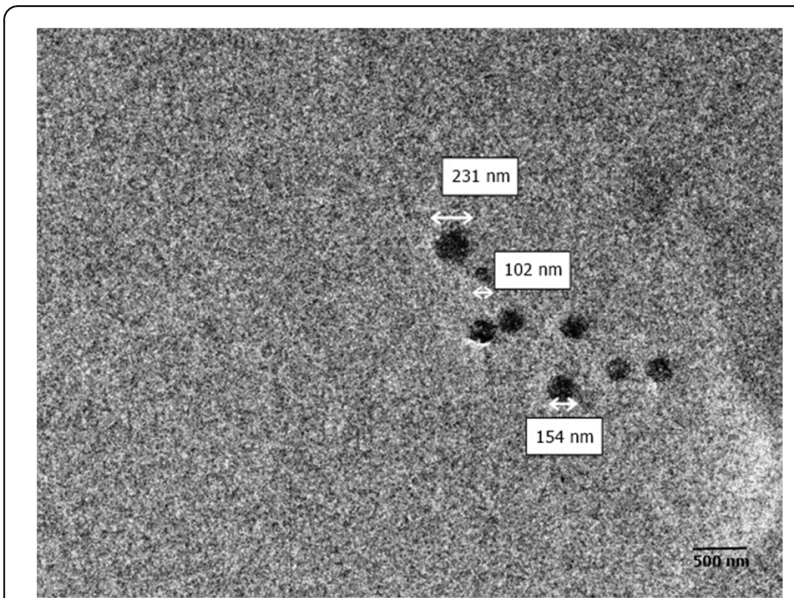

Fig. 8 TEM image of the optimized Eudragit nanoparticles

\section{Shelf life study of LB-NP-loaded contact lenses}

Shelf life was performed to evaluate the drug leached from the nanoparticle-loaded contact lenses in the packed liquid. The drug-incorporated lens was stored in the packaging solution for a period of 3 months at room temp. Then, the lenses were removed and the packed solution was analysed for LB content leached in packed solution for a period of 3 months using a UV-vis spectrophotometer (UV 1800, Shimadzu, Japan) [31].

\section{Results}

\section{FTIR analysis}

The infrared spectrum of levobunolol showed a $\mathrm{C}-\mathrm{O}$ bond due to a strong band seen at $1239 \mathrm{~cm}^{-1}$. Other characteristic bands seen in the spectra which authenticate it to be of the $\mathrm{LB}$ are $\mathrm{C}=\mathrm{C}$ strong stretching band of benzene ring observed as a doublet at 1475 which is characteristic of the benzene skeletal. $\mathrm{C}-\mathrm{N}$ band at 1264 $\mathrm{cm}^{-1}$ further confirms the drug. A weak $\mathrm{C}-\mathrm{H}$ stretching band at $2805 \mathrm{~cm}^{-1}$ shows the presence of alkane. An N$\mathrm{H}$ stretching band at $3368 \mathrm{~cm}^{-1}$ was also observed. Hence, all the bands were found to be in correlation with the chemical structure of LB. Thus, this characterizes the drug to be LB as shown in Fig. 3. Eudragit S100 showed peaks at $1446.14 \mathrm{~cm}^{-1}, 1723.02$ $\mathrm{cm}^{-1}$ due to $\mathrm{CH}_{3}$ bond and the presence of $\mathrm{C}=\mathrm{O}$ ester respectively as shown in Fig. 4, confirming the structure of Eudragit S100. PVA showed the FTIR spectrum of PVA showed the stretching vibrations of $\mathrm{CH} 2$ asymmetric stretching at $2980.82 \mathrm{~cm}^{-1}$ and $\mathrm{C}-\mathrm{O}$ stretching vibrations at $1087.49 \mathrm{~cm}^{-1}$ as shown in Fig. 5. No significant peak shift was observed in the physical mixture of levobunolol hydrochloride $\left(1238 \mathrm{~cm}^{-1}, 1479 \mathrm{~cm}^{-1}, 1264.82\right.$ $\left.\mathrm{cm}^{-1}, 2806 \mathrm{~cm}^{-1}, 3368.34 \mathrm{~cm}^{-1}\right)$, Eudragit S100 (1457 $\left.\mathrm{cm}^{-1}, 1676.16 \mathrm{~cm}^{-1}\right)$ and PVA $\left(2979.05 \mathrm{~cm}^{-1}, 1056 \mathrm{~cm}^{-1}\right)$ as shown in Fig. 6.

\section{Characterization of Eudragit S100 nanoparticles Physiochemical evaluation}

Particle size, zeta potential and polydispersity index (PDI) of ES 100 nanoparticles are reported in Table 2. The size formulated by nanoprecipitation methodology was obtained in Nano range, indicating its suitability. From Table 2, it is clearly seen that the minimum particle size was found at 3:2 and 2:1 ratios of Eudragit S100 and polyvinyl alcohol (Fig. 7). The PDI obtained by nanoprecipitation methodology indicates the uniform size distribution of prepared nanoparticles. The highest PDI values were found at 3:2 and 2:1 ratios of Eudragit S100 and polyvinyl alcohol. It was observed that as the Eudragit S100 concentration increased, the particle size of nanoparticles decreased.

The zeta potential on Eudragit S100 nanoparticles was found negative for all nanoparticle's batches (Table 2), although there was really no perceptible variation between the values of zeta potential of the various nanoparticles. The optimum value of zeta potential was found to be $-22.2 \pm 2.76 \mathrm{mV}$ at the 3:2 ratio of Eudragit S100 and polyvinyl alcohol. Eudragit S100 has characteristic dissolution behaviour at $\mathrm{pH}$ 7.0. So at $\mathrm{pH}$ 7.0, it became highly ionized resulting in high zeta potential which can provide an electric repulsion to avoid particle aggregation.

Table 3 FDA-approved silicon contact lenses and their properties

\begin{tabular}{|c|c|c|c|c|c|}
\hline Commercial contact lens & Iconnect & Slip-on & Optima 38 & Acuvue Moist & Softlens \\
\hline Manufacturer & Bausch \& Lomb & Aqualens & Baush \& Lomb & Johnson \& Johnson & Bausch \& Lomb \\
\hline Hydrogel material & Hilafilcon B & Omafilcon A & Polymacon & Etafilcon A & Hilafilcon B \\
\hline Percentage of water content & 48 & 58 & 38.6 & 58 & 56 \\
\hline Oxygen transmissibility & 10 & $28-36.7$ & $8.5-24.3$ & $23.8-28$ & 22 \\
\hline FDA group & $\|$ & $\|$ & III & IV & $\|$ \\
\hline \multirow[t]{2}{*}{ Water content } & High & High & Low & High & High \\
\hline & Non-ionic & Non-ionic & Ionic & Ionic & Non-ionic \\
\hline
\end{tabular}


Table 4 Drug uptake by contact lenses after $24 \mathrm{~h}$ of soaking period

\begin{tabular}{ll}
\hline $\begin{array}{l}\text { From LB solution-loaded contact } \\
\text { lenses }(\boldsymbol{n}=\mathbf{3})\end{array}$ & $\begin{array}{l}\text { From LB-NP-loaded contact } \\
\text { lenses }(\boldsymbol{n}=\mathbf{3})\end{array}$ \\
\hline $0.6851 \mathrm{mg} \pm 0.23$ & $0.5676 \mathrm{mg} \pm 0.024$ \\
\hline
\end{tabular}

\section{Drug entrapment study}

The distribution of percentage entrapment efficiency among different formulations of Eudragit S100-based LB-loaded nanoparticles is shown in Table 2. Maximum entrapment of LB is found at the 3:2 ratio of Eudragit S100 and polyvinyl alcohol. It was observed that as the concentration of Eudragit increased, keeping concentrations of PVA constant, there was an increase in entrapment efficiency.

It is clearly seen that the formulation (F3) having 3:2 ratio of ES 100 and PVA is the optimized formulation, depending on the findings of size, zeta potential and efficiency of entrapment [37].

\section{Transmission electron microscopy (TEM)}

A transmission electron microscope was used for the visualization of optimized Eudragit nanoparticle formulation (F3). The nanoparticles were found to be spherical in shape, and they appeared dark in bright surroundings. The droplet size was approximately 178 to $246 \mathrm{~nm}$ in TEM images, and this was consistent with our previous results obtained by using a size analyser (Fig. 8).

\section{Development of levobunolol nanoparticle-loaded contact lens}

\section{Selection of contact lenses}

For this study, five types of contact lenses are purchased from various manufacturers in India for the study and checked their water content and oxygen permeability as mentioned in Table 3. From the table, it is clearly seen that AquaLens " "Slip-on" contact lens containing Omafilcon hydrogel material possesses the maximum water contact and highest oxygen transmissibility while the other four contact lenses did not possess significant oxygen transmissibility and water content [38].

\section{Drug uptake by contact lenses}

After $24 \mathrm{~h}$ of drug loading, the lenses were removed from LB-NPs as well as from LB solution and soaked in $10 \mathrm{~mL}$ of ethanol for $24 \mathrm{~h}$ to extract the absorbed drug from the matrix of hydrogel contact lens. Then, the ethanolic solution was obtained by a UV spectrophotometer at $257 \mathrm{~nm}$. The drug uptake by the contact lenses from both the loading solution is mentioned in Table $4[39,40]$. No further drug uptake was observed by the contact lens.

\section{Characterization of the prepared LB-NP-loaded contact lenses Physical appearance}

The NP-loaded contact lenses were found to be transparent, and there was no change in colour as compared to the control lenses when inspected visually as shown in Fig. 9.

\section{Optical clarity study}

The optical clarity was evaluated by noting the transmittance of control as well as nanoparticle-loaded contact lens at $630 \mathrm{~nm}$ in a UV-visible spectrophotometer, and the lens was found to be clear and exhibited maximum transmittance of $97.15 \%$ in the UV range as evident from Table 5 . Both the control and NP-loaded contact lenses show similar percentage transmittance; this is due to nanoparticles loading to the contact lens matrix.

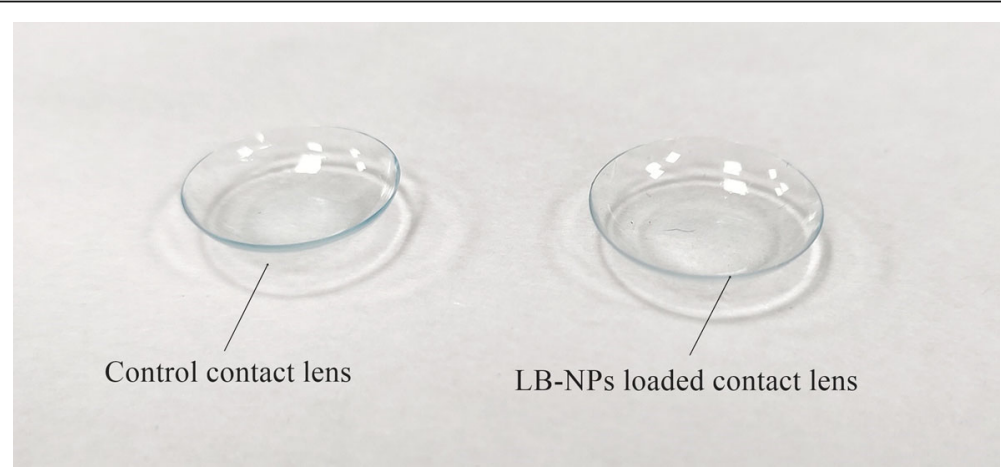

Fig. 9 Visual appearance of the control contact lens and LB-NP-loaded contact lens 
Table 5 Percentage transmittance and ESI of the contact lens

\begin{tabular}{llllll}
\hline \% transmittance of contact lenses & & Equilibrium swelling index $(\%)$ \\
\cline { 1 - 1 } \cline { 5 - 6 } & Control contact lens $(\boldsymbol{n}=\mathbf{3})$ & NP-loaded contact lens $(\boldsymbol{n}=\mathbf{3})$ & & Drug solution-loaded lenses $(\boldsymbol{n}=\mathbf{3})$ & LB-NP-loaded lenses $(\boldsymbol{n}=\mathbf{3})$ \\
\hline $97.923 \pm 0.189$ & $97.15 \pm 0.261$ & $27.016 \pm 0.310$ & $25.47 \pm 0.520$ \\
\hline
\end{tabular}

\section{Equilibrium swelling studies}

The swelling index of LB-NP-loaded contact lenses is compared with that of drug solution-loaded contact lenses to identify any significant changes in results due to loading as shown in Table 5. The NP-loaded contact lenses swell slightly less than the control contact lens.

This suggests that the presence of Eudragit nanoparticles lead to increased crosslinking in the contact lenses. Increased crosslinking will also lead to slow and sustained release of the drug.

\section{In vitro drug release in simulated tear fluid}

The cumulative drug release in fresh simulated tear fluid from LB-NP-based lenses incorporated with $0.5676 \mathrm{mg}$ of LB is shown in Fig. 10. In the release studies, an initial release was burst as obtained by all batches, which can be due to the drug's low molecular weight and high solubility of LB in STF. Then, sustained release for up to 12 days was achieved with a percentage of $82.33 \pm 0.34$. Also, during the entire test, the lenses looked translucent, suggesting the existence of medication at nanosize following dissolution of Eudragit S100, whereas around 91.12\% \pm 0.900 of the LB is released in 3 days from the contact lenses showing high burst release.

\section{Determination of drug release kinetics}

Table 6 shows the slope and $r^{2}$ values obtained from the zero order, first order, Peppas and Higuchi models. It was observed that the release of the drug from the developed contact lenses was considered to be following zero order kinetics as it showed the highest $r^{2}$ value and follows the Peppas model for drug release. The plot's $n$ value was 1.39 , indicating that the mechanism for releasing drugs is super case II transport.

\section{Ex vivo transcorneal permeation studies}

Goat cornea excised freshly was being carefully dissected from the eyeball along with the $2-4 \mathrm{~mm}$ of encircling sclera tissue and rinsed with saline water to remove any adhering pigments as shown in Fig. 11. The results obtained for percentage cumulative drug release from optimized LB-NP-loaded contact lenses and LB solution-incorporated contact lenses are shown in Fig. 12.

As the $5676 \mu \mathrm{g} \pm 0.024$ amount of drug was loaded in the lens, LB-NP-loaded contact lenses showed the higher permeation across the freshly excised goat cornea $(6.756 \% \pm 0.170)$ in $6 \mathrm{~h}$ as compared with the LB solution-loaded contact lenses $(3.033 \% \pm 0.088)$.

\section{In vitro release profile}

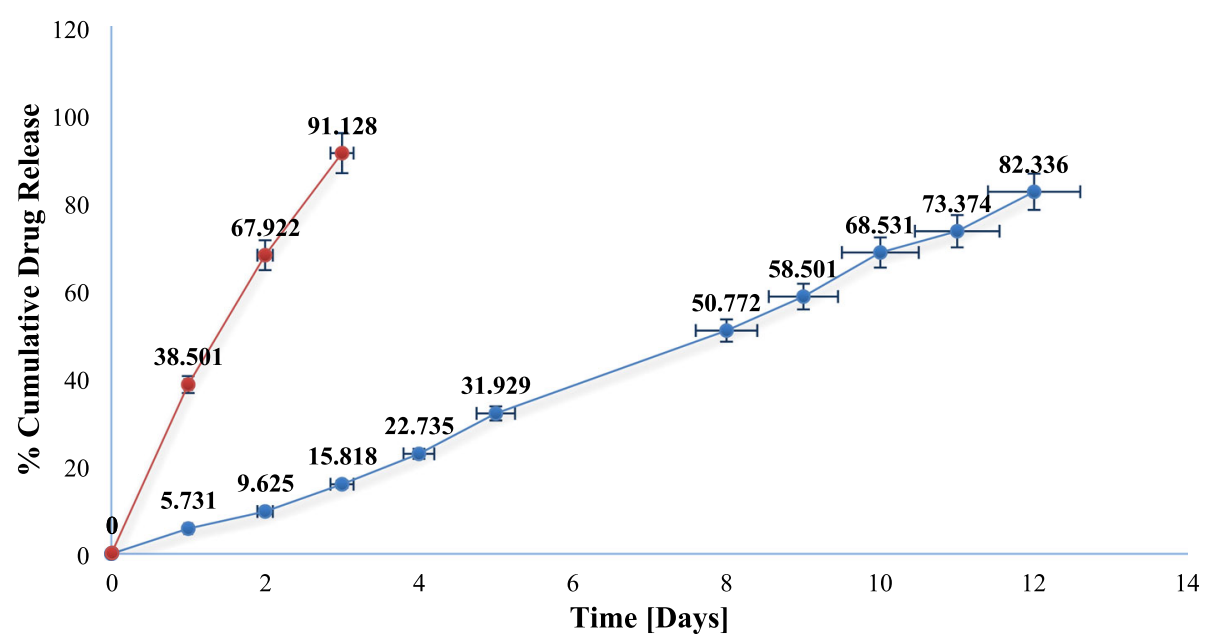

Fig. 10 Cumulative drug release profile of LB solution- and LB-NP-loaded contact lenses 
Table 6 Release kinetics

\begin{tabular}{lll}
\hline Model & Slope $(\boldsymbol{n}$ value $)$ & $\boldsymbol{r}^{\mathbf{2}}$ \\
\hline Zero order & 6.9537 & 0.9961 \\
First order & -0.0018 & 0.9955 \\
Higuchi model & 25.67 & 0.8979 \\
Peppas model & 1.39 & 0.9052 \\
\hline
\end{tabular}

\section{Shelf life study of LB-NP-loaded contact lens}

The drug release from NP-loaded contact lenses after 1 , 2 and 3 months was obtained as $1.210 \% \pm 0.109,1.894 \%$ \pm 0.161 and $2.381 \% \pm 0.091$ of leaching, respectively. Also, the drug content as measured by the UV spectrophotometer after 1,2 and 3 months was obtained as $98.84 \% \pm 0.41,98.21 \% \pm 0.15$ and $97.88 \% \pm 0.63$, respectively. This data suggests that considering $5676 \mu \mathrm{g} \pm$ 0.024 of loading, the drug loss during the storage period was not significant. The Eudragit nanoparticles therefore prevented the drug loss in the packed solution during the shelf life of the therapeutic contact lenses.

\section{Discussion}

The presented work successfully revealed the potential advantages of delivering levobunolol from Eudragit nanoparticles through contact lenses for glaucoma management. The DLS report confirmed the uniform distribution of nanoparticles and their nanosize.

The formulation batch was found to be optimized with the 3:2 ratio of ES 100 to PVA. Optimized nanoparticles showed particle size and zeta potential of $102.42 \mathrm{~nm} \pm$ 15.56 and $-22.2 \mathrm{mV} \pm 2.76$. The maximum entrapment efficiency was found to be $86.99 \% \pm 1.90$.

Depending on the water contact and oxygen transmissibility [38], Aqua Lens Slip-on contact lens containing Omafilcon hydrogel material was selected for the study.
The maximum drug uptake by the contact lenses was $0.5676 \mathrm{mg}$ after $24 \mathrm{~h}$ of the soaking period [39, 40]. The LB-NP-loaded contact lenses exhibit 97\% UV transmittance in the UV region, which shows that the nanoparticle loading did not interfere with the contact lenses' optical and physical properties. The decrease in the swelling index of LB-NP-loaded contact lens data indicates that the presence of nanoparticles contributes to increased crosslinking in the gels due to the use of polymers in nanoparticle preparation [41].

The Eudragit S100 NPs prevented the loss of drug in the packaging solution during the shelf life of 3 months.

The in vitro drug release study from LB-NP-based lenses demonstrates initial burst release, followed by a sustained therapeutic release for up to 12 days. This indicates the controlled release of LB from $\mathrm{pH}$-sensitive Eudragit S100 nanoparticles. Eudragit nanoparticle dissolution led to the development of Nano cavities, which regulated the rate of drug release from hydrogels. It also was found that within the nanoparticles, some portion of the medication stayed indefinitely bound while $91 \%$ of the drug from LB solution-incorporated lens was released within 3 days because no layer was formed on the lens surface which may provide for the medication slow release.

The drug release from the developed contact lenses was found to follow zero order kinetics with an $R^{2}$ value of 0.9961 . Fickian diffusion with swelling was the exact real mechanism behind drug release from LB-NP contact lenses.

The ex vivo permeation data suggest that there is more than 40-50\% permeation achieved with LB-NPloaded contact lenses as compared to marketed eye drops due to the presence of POLTF. This increase in the permeation through nanoparticle-loaded contact lenses across the cornea is due to the presence of

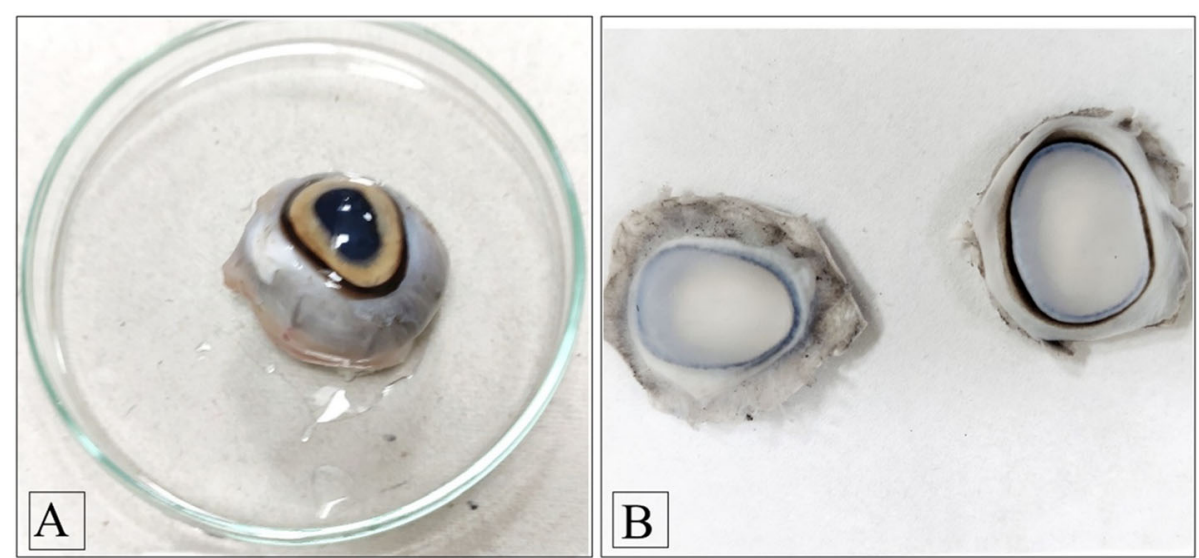

Fig. 11 Images showing the a freshly excised goat cornea and $\mathbf{b}$ dissected goat cornea with adhering sclera 


\section{Cumulative drug release from goat cornea}

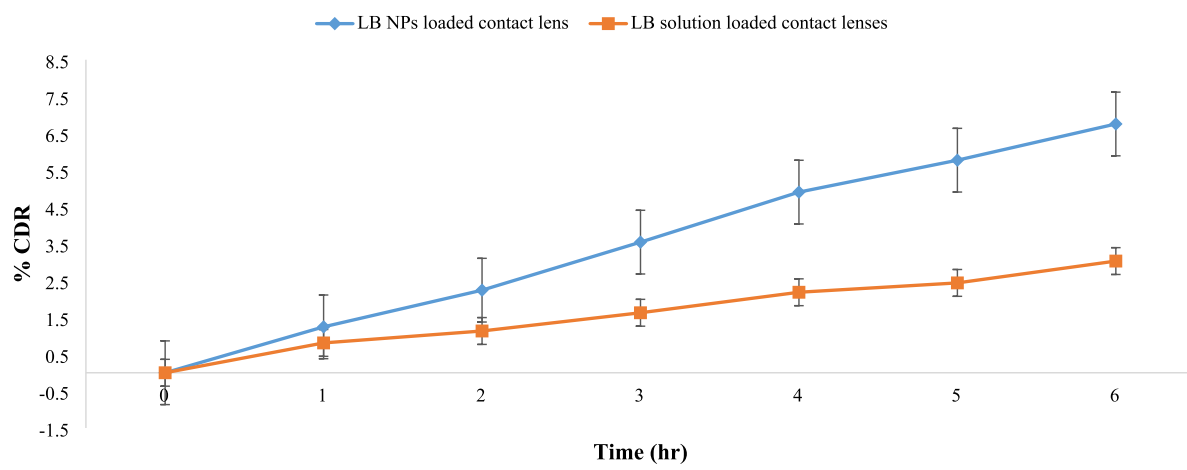

Fig. 12 Graph showing cumulative drug release profile through the goat cornea

POLTF from which the medication is administered gradually into the precorneal region [36].

\section{Conclusion}

The utilization of contact lenses as a system for delivery of medication is significantly important in improving the efficiency of ocular treatment to overcome the limitations of poor bioavailability, patient incompliance and reduced efficacy associated with conventional eye drop formulations. Loading of the medication into the contact lenses enhances the release duration of the drug from several hours to several days. The presented work successfully revealed the potential advantages of delivering levobunolol from Eudragit nanoparticles through contact lenses for glaucoma management. The optimized nanoparticle formulation was discrete and spherical. The equilibrium swelling index and transmittance of nanoparticle incorporated into contact lenses showed better results when compared to drug solution-loaded lenses. The in vitro release of the drug study demonstrates burst release initially, preceded by a sustained therapeutic release for up to 12 days. This indicates the controlled release of LB from $\mathrm{pH}$-sensitive Eudragit S100 nanoparticles. The ex vivo permeation data suggest that there is more than $50 \%$ permeation with LB-NP-loaded contact lenses as compared to marketed eye drops due to the presence of POLTF. On the basis of the results, it is inferred that effective glaucoma treatment is possible through the development of contact lenses loaded with LB-NPs, which releases the drug in a controlled way over an extended period of time.

\section{Acknowledgements}

The authors are thankful to Piramal Healthcare Pvt. Ltd., Mumbai, India, and Evonik India Pvt. Ltd., Mumbai, India, for providing gift samples of levobunolol and Eudragit S100, respectively.
Authors' contributions

NK contributed to the drafting, design and analysis of the data. RA contributed to the drafting, design and analysis of the data. MKC contributed to draft revision and data interpretation. All "authors" have read and approved the final manuscript.

\section{Funding}

This research did not receive any specific grant from funding agencies in the public, commercial, or not-for-profit sectors.

Availability of data and materials

All data and material are available upon request.

Ethics approval and consent to participate

Not applicable

\section{Consent for publication}

Not applicable

\section{Competing interests}

The authors declare that they have no competing interests.

Received: 6 July 2020 Accepted: 12 October 2020

Published online: 27 November 2020

\section{References}

1. Casson RJ, Chidlow GW, John PM, Crowston JG, Goldberg I (2012) Definition of glaucoma: clinical and experimental concepts. Clin Exp Ophthal 40(4): $341-349$

2. Weinreb RN, Khaw PT (2004) Primary open-angle glaucoma. Lancet 363(9422):1711-1720

3. Tham YC, Li X, Wong TY, Quigley HA, Aung T, Cheng YC (2014) Global prevalence of glaucoma and projections of glaucoma burden through 2040: a systematic review and meta-analysis. Ophthal 121(11):2081-2090

4. Bourlais CL, Acar L, Zia H, Sado PA, Needham T, Leverge R (1998) Ophthalmic drug delivery systems--recent advances. Prog Retin Eye Res 17(1):33-58

5. John CL, Robert ER, Rajni J (2006) Ophthalmic preparations. Remington the science and practice of pharmacy 21(1):866-868

6. Gulsen D, Chauhan A (2004) Ophthalmic drug delivery through contact lenses. Investigative Ophthal Vis Sci 45(7):2342-2347

7. Alvarez-Lorenzo C, Hiratani H, Concheiro A (2006) Contact lenses for drug delivery. Am J Drug Deliv 4(3):131-151

8. Xinming L, Yingde C, Lloyd AW (2008) Polymeric hydrogels for novel contact lens-based ophthalmic drug delivery systems: a review. Cont Lens Anterior Eye. 31:57-64

9. Carmen AL, Haruyuki H, Angel C (2006) Review article on contact lenses for drug delivery. Arm J Drug Deliv 4(3):131-151

10. Khalid M, El-Sawy HS (2017) Polymeric nanoparticles: promising platform for drug delivery. Int J Pharm 528(1-2):675-691 
11. Jung HJ, Abou-Jaoude M, Carbia BE, Plummer C, Chauhan A (2013) Glaucoma therapy by extended release of timolol from nanoparticle loaded silicone-hydrogel contact lenses. J Control Release 165(1):82-89

12. Duzman E, Ober M, Schar r A, Leopold I H (1982) A clinical evaluation of the effects of topically applied levobunolol and timolol on increased intraocular pressure. Am J Ophthalmol 94:318-322.

13. Cinotti A, Cinotti D, Grant W (1985) Levobunolol vs timolol for open-angle glaucoma and ocular hypertension. Am J Ophthalmol 99(1):11-17

14. Gonzalez JP, Clissold SP (1987) Ocular levobunolol: a review of its pharmacodynamic and pharmacokinetic properties and therapeutic efficacy. Drugs 34:648-661

15. BETAGAN-Levobunolol hydrochloride solution, Allergan U.S.A (2005). https:// www.accessdata.fda.gov/drugsatfda_docs/label/2017/019219s029lbl.pdf. Accessed 01 July 2020

16. Yoo J-W, Giri N, Lee CH (2011) pH-sensitive Eudragit nanoparticles for mucosal drug delivery. International journal of Pharmaceutics 403: 262-267

17. Gupta VK, Assmus MW, Beckert TE, Price JC (2001) A novel pH- and timebased multiunit potential colonic drug delivery system. Int J Pharm 213: 93-102

18. Creech JL, Chauhan A, Radke CJ (2001) Dispersive mixing in the posterior tear film under a soft contact lens. Ind Eng Chem Res 40(14):3015-3026

19. McNamara NA, Polse KA, Brand RJ, Graham AD, Chan JS, McKenney CD (1999) Tear mixing under a soft contact lens: effects of lens diameter. Am J Ophthalmol 127(6):659-665

20. Sedlacek J (1965) Possibilities of application of ophthalmic drugs with the aid of gel-contact lenses. Cesk Ophtalmol 21:509-512

21. Aida M, Wassim A, Ismaiel T, Trefi S (2015) Influence of nanoprecipitation method parameters on nanoparticles loaded with gatifloxacin for ocular drug delivery. Int J Sci Res 3:1-12

22. Jung HJ, Chauhan A (2012) Temperature sensitive contact lenses for triggered ophthalmic drug delivery. Biomaterials 33(7):2289-2300

23. Peng C-C, Burke MT, Carbia BE, Plummer C, Chauhan A (2012) Extended drug delivery by contact lenses for glaucoma therapy. J Control Release 162(1):152-158

24. Jung HJ, Abou JM, Carbia BE (2013) Glaucoma therapy by extended release of timolol from nanoparticle loaded silicon hydrogel contact lenses. J Control Release 165:82-89

25. White CJ, McBride MK, Pate KM, Tieppo A, Byrne ME (2011) Extended release of high molecular weight hydroxypropyl methylcellulose from molecularly imprinted extended wear silicone hydrogel contact lenses. Biomaterials 32(24):5698-5705

26. Maulvi FA, Soni TG, Shah DO (2014) Extended release of timolol from ethyl cellulose micro particles laden hydrogel contact lenses. J Pharm Appl Sci 1: $17-23$

27. Yoo JW, Giri N, Lee CH (2011) pH-sensitive Eudragit nanoparticles for mucosal drug delivery. Int J Pharm 403:262-267

28. Mohammadi S, Jones L, Gorbet M (2014) Extended latanoprost release from commercial contact lenses: in vitro studies using corneal models. Plos 9 : e106653

29. Hehl ME, Beck R, Luthard K, Guthoff R, Drewelow B (1999) Improved penetration of aminoglycosides and fluoroquinolones into the aqueous humour of patients by means of Acuvue contact lenses. Eur J Clin Pharmacol 55:317-323

30. Li CC, Chauhan A (2006) Modelling ophthalmic drug delivery by soaked contact lenses. Industrial \& Engineering Chemistry Research 45(10):37183734

31. Manjunatha, K., \& Kulkarni, G. (2013). Design, development and evaluation of controlled release levobunolol hydrochloride ocular inserts for glaucoma therapy. 3(3): 87-97.

32. Dash S, Murthy PN, Nath L, Chowdhury P (2010) Kinetic modeling on drug release from controlled drug delivery systems. Acta Pol Pharm 67(3):217-223

33. Maulvi FA, Shaikh AA, Lakdawala DH, Desai AR, Pandya MM, Singhania SS (2017) Design and optimization of a novel implantation technology in contact lenses for the treatment of dry eye syndrome: in vitro and in vivo evaluation. Acta biomaterialia 53:211-221

34. Ali M, Horikawa S, Venkatesh S, Saha J, Hong JW, Byrne ME (2007) Zeroorder therapeutic release from imprinted hydrogel contact lenses within in vitro physiological ocular tear flow. J Control Release 124(3):154-162
35. Gupta H, Aqil M, Khar RK, Ali A, Bhatnagar A, Mittal G (2011) Biodegradable levofloxacin nanoparticles for sustained ocular drug delivery. J Drug Target. 19:409-417

36. Mahboobian MM, Seyfoddin A, Aboofazeli R, Foroutan SM, Rupenthal ID (2019) Brinzolamide-loaded nanoemulsions: ex vivo transcorneal permeation, cell viability and ocular irritation tests. Pharm Dev Technol 24(5):600-606

37. Hasan A (2012) Formulation and evaluation of dorzolamide hydrochlorideloaded nanoparticles as controlled release drug delivery system. Asian J Pharm 6:67-73

38. Musgrave C, Fang F (2019) Contact lens materials: a materials science perspective. Materials 12(2):261

39. Tojo K (2004) A pharmacokinetic model for ocular drug delivery. Chem Pharm Bull 52:1290-1294

40. Karlgard CC, Wong NS, Jones LW, Moresoli C (2003) Invitro uptake and release studies of ocular pharmaceutical agents by silicon-containing and $\mathrm{p}$ HEMA hydrogel contact lens materials. Int J Pharm 257(1-2):141-151

41. Brazel CS, Peppas NA (1999) Dimensional analysis of swelling of hydrophilic glassy polymers with subsequent drug release from relaxing structures. Biomaterials 20(8):721-732

\section{Publisher's Note}

Springer Nature remains neutral with regard to jurisdictional claims in published maps and institutional affiliations.

\section{Submit your manuscript to a SpringerOpen ${ }^{\circ}$ journal and benefit from:}

- Convenient online submission

- Rigorous peer review

- Open access: articles freely available online

- High visibility within the field

- Retaining the copyright to your article

Submit your next manuscript at $>$ springeropen.com 